\title{
THE BASES OF HARMONIZATION OF REGULATIONS \\ ON FOOD PRODUCTION AND LABELING IN THE CUSTOMS UNION WITHIN THE EURASIAN ECONOMIC COMMUNITY
}

\author{
Mark SHAMTSYAN $^{1}$ \\ St. Petersburg State Institute of Technology (Technical University) \\ Moskovsky prospect, 26, St. Petersburg, 190013, Russia
}

\begin{abstract}
The Eurasian Economic Community (EurAsEC) is an international economic organization created to effectively advance the process of forming a Customs Union and Common Economic Space by member states and also to implement other goals and objectives connected with the enhancement of integration in the economic and humanitarian spheres. One of the major challenges for the successful functioning of the common customs space of the members of the Customs Union, is the harmonization and unification of the legislation, including food legislation of the countries - members of the Customs Union. Unification of the legislation related to the labeling of food products will promote the trade and will ensure the awareness of the consumers.
\end{abstract}

Keywords: Customs Union, Food legislation, Food labeling.

\section{INTRODUCTION}

The Treaty on the Establishment of EurAsEC was signed in Astana, Kazakhstan on 10 October, 2000, and came into effect on 30 May, 2001, after being ratified by all the EurAsEC member states.

Five states - Belarus, Kazakhstan, Kyrgyzstan, Russia and Tajikistan - have been members of EurAsEC since its formation. Ukraine and Moldova have

${ }^{1}$ Corresponding author. Mailing address: St. Petersburg State Institute of Technology (Technical University)Moskovsky prospect, 26, St. Petersburg, 190013, Russia. E-mail: mark.shamtsyan@yandex.ru 
had the status of EurAsEC observer since May 2002, and Armenia since January 2003.

In accordance with the statutory goals and objectives of the Community and guided by the principle of multispeed integration, the Customs Union was created by Belarus, Kazakhstan and Russia in 2007-2010. On the next stage of integration starting on 1 January, 2012, the Common Economic Space (CES) of three countries started operating. Its full function work will begin in 2015. Other Community states will join the Customs Union and the CES when they are ready.

As a model for the formation of technical regulations of the Customs Union (CU), the model of the European Union (EU) was used. Armenia is expected to join $\mathrm{CU}$ in mid-2014. Intention of accession in the near future to the Customs Union was expressed by Kyrgyzstan.

\section{FOOD PRODUCTION AND LABELING IN THE CUSTOMS UNION}

In 2010, the decision of the Interstate Council of the Eurasian Economic Community (the supreme body of the Customs Union) at the level of Heads of Government adopted the most important international treaties that form the legal base of CU.

Some of them are directly related to the objects of the food industry:

- The agreement on the treatment of products subject to mandatory conformity assessment (attestation), in the customs territory of the Customs Union on 11.12.2009;

- Customs Union Agreement on Sanitary Measures on 11.12.2009;

- Customs Union Agreement on veterinary and sanitary measures from 11.12.2009;

- The agreement on common principles and rules of technical regulation in the Republic of Belarus, the Republic of Kazakhstan and the Russian Federation from 18.11.2010.

The basic principle of the system of technical regulation in the territory of the Customs Union is the consistent separation of the requirements to:

- Mandatory to comply with the requirements of technical regulations;

- intended for voluntary application of the standards

The fundamental meaning of this distinction lies in the conversion of all the mandatory requirements into legislation. As the technical regulations contain minimum requirements for the safety, the requirements of any standard, by definition, cannot be below the relevant requirements of technical regulations. 
As a result of joint work of the specialists of $\mathrm{CU}$ on the projects of the regulations on food products, food supplements, food packaging and labeling, a number of so-called horizontal technical regulations (TR) has been developed

In July of.2012 the first CU horizontal TR 005/2011 "On the safety of the packaging" was introduced and from 01.07.2013 the following regulations were put into effect:

- CU TR 021/2011 "On Food Safety"

- CU TR 022/2011 "Food products in part of their labeling"

- CU TR 027/2012 "On the safety of certain types of special food products, including dietary medical and dietary prophylactic nutrition"

- CU TR 029/2012 "Safety of food additives, flavorings and processing aids"

At the same time a series of vertical technical regulations were also developed.

Requirements of horizontal regulations are common for large groups of products or processes of their production. Since technical regulations "On Food Safety" contains general requirements for the safety of all food products, the vertical regulations contain some additional requirements for safety and quality of specific groups and types of products.

The main purpose of the CU regulations - set in the common customs territory of the mandatory uniform for the application and enforcement of the requirements for food products in terms of their safety, packaging and labeling, as well as the prevention of actions misleading purchasers (consumers), and to ensure the free movement of food products manufactured o the Customs Union territory.

All food products, which are the objects of the CU regulations, should be marked by a single marked of circulation of the products on the market of the Member States of the Customs Union, after the assessment (confirmation) of compliance with the relevant regulations.

A single mark (Eurasian Conformity) would indicate that the marked products are passed all of the assessment procedures (confirmation) of compliance set in the technical regulations of the Customs Union and meets the requirements of these regulations.

This mark should be applied to each unit of production, packaging and accompanying documentation.

Regulations adopted by the CU, as the documents of same orientation, have structural differences. The requirements of horizontal and vertical regulations 
should be applied at the same time, as the released products (foods, food additives and processing aids, packing and packaging materials, etc.) must meet the requirements of all regulations of $\mathrm{CU}$ regulations, the effect of which apply to them. Requirements of horizontal regulations complement the relevant requirements of vertical ones.

For CU member states this is the first experience of simultaneous implementation of the whole system of international documents. In order to successfully accomplish the task, a transition period and the appropriate methodological framework is required.

Evidentiary materials that confirm information about the product and its production process required for the formation of labeling are the following documents:

- documents certifying that the product meets the requirements of regulations (the declaration of conformity, certificate of state registration, the certificate of conformity of the finished product);

- documents obtained by the manufacturer from a third party (the declaration of conformity, certificate of state registration, the certificate of conformity of raw materials, components, packaging, test reports, expert opinions of other organizations, the conclusion of the expert committees, etc.);

- documents and information received (prepared) by the manufacturer itself (data production $\operatorname{logs}$, and data obtained by testing the product, the data obtained by calculation, the specifications for the product (component, dietary supplement, packaging); trademark certificate, a certificate for a patent, etc.)

For the gradual formation of the text labeling of consumer packaging scheme of information provision is designed, which establishes the relationship of specific parts of the label to the documents pursuant to which the product is made and to evidence-based information and materials.

Inscriptions and texts in the labeling information must be printed in Russian and in the languages of the Member States of the Customs Union. Information for the same consumer package set out in various languages, to be completely identical. If the product comes to the territory of the Customs Union from the other countries, the information provided on the packaging must be set forth in the official languages of the Member States of CU, comply with the legislation and to be identical to the text of the original labeling, mandatory labels supplemented, if necessary. The incorrect 
translation or inaccurate representation of information can mislead the consumer, thereby causing unwanted effects.

The requirements for the font labeling information in the legislation, standards and guidelines are not mentioned, except for the requirements for the font of certain mandatory labels.

Product name led to the front of the package or on the main display wall, using a font size of at least 9.5 point size. If the consumer packaging has a capacity of less than $100 \mathrm{~mL}(\mathrm{~g})$ the name of the product as indicated on the front of the pack, but at the same font size should be at least 8.5 point size.

Labeling of food products must not contain in the consumer packaging the images of food products, which are absent, food component, or an image that has not been used in the manufacture of the product. It is allowed the application of image of ready meal, for the preparation of which is applied said component, with the obligatory indication of the inscription "option of cooking."

In all documents in the field of consumer protection and TR CU for milk is not allowed to post images of children on the consumer package of breast milk substitutes.

The name of the product is one of the important elements of the identification markings.

The name is formed from the technical name of the product and invented names. The name of the product may be accompanied by the image of the trademark.

Invented names used to distinguish the characteristics of similar products. Such names are formed from the words or phrases that may not reflect consumer product. Invented name is given on the labeling of consumer packaging, if such information is recorded in the relevant product documentation. So invented names provides to the manufacturer an additional opportunity to attract the attention of the consumer by using the "attractive words" without spending efforts for registration of the trademark.

TR CU for milk prohibits the use of the basic regulated terminology in invented names of those products that do not meet the declared properties by their identity parameters.

According to TR CU 022/2012 trademark is related to the additional information. The trademark is used as a special form of marking of goods that can distinguish the goods of one manufacturer of similar products from other manufacturers. Often registered trademarks associated by the consumer as with the product manufacturer, as with specific groups of products. 
Product manufacturers often place on the packages images of several trademarks. Such an arrangement is possible with the appropriate entries in the trademark certificate.

Requirements for instruction in labeling of consumer packaging for information on the name of the manufacturer and its location, the organization receiving complaints from consumers, information about the importer are detailed set out in the Article 4 of the 4.8 TR CU022/12.

In accordance with TR TC 022/2011 data on the quantity of packaged products are classified as mandatory for labeling. Thus, Article 4, Section 4.5 contains full information on how to declare the quantity of packaged products. The requirements apply to products packed as in consumer packaging or in multipacks, as in the shipping container.

The quantity of packaged food products is indicated on the labeling of these products in terms of volume, mass or amount (number). And it is allowed to use the abbreviated names of the units.

It is allowed simultaneous use of two values to indicate the number of food products, such as weight and volume, or weight and number of pieces.

If food products are placed in liquid medium, e.g. water, aqueous sugar solutions, aqueous solutions of salts or of food acids, brine, vinegar, fruit or vegetable juices, additional weight or volume of food placed in a liquid medium to be given together with the volume or weight of the food product with a liquid medium. This requirement also applies to food products, placed in a liquid medium, followed by freezing.

Indication of the indefinite number of packaged food products and specification of a range of values of packaged food products not permitted.

Documents that establish standards and requirements for information to the consumer, strictly and clearly define how it is necessary to declare the list of ingredients on the label or the product. This is primarily, for the protection of human life and health, prevention actions that may mislead consumers and to ensure fair practices in food trade. Secondly, the list of components that make up the product, as well as the name, reveals the nature of the origin of the product - its raw materials and technological features, and thus is directly related to product

The labeling element "the product composition" is formed from the list of components that make up the product, includes additional information about the distinctive characteristics of the product, and may also contain mandatory (warning) labels related to this item.

Ingredients included in the food should be listed in descending order of their mass fraction as it was for the time of the production of food products, unless 
otherwise provided by the technical requirements regulations of the Customs Union on certain types of food products. Immediately prior to the indication of these components must be placed inscription "Composition".

In the case of presence of the composite food component (consisting of two or more components) in the food product a list of all the components that make up this composite component or constituent states with an addition to it in brackets components in descending order of their mass fraction should be indicated. If the mass fraction of the composite component is $2 \%$ or less, it is allowed not to specify the sub-components, with the exception of food additives, flavorings and their constituent supplements biologically active substances and medicinal plant components, components obtained using GMO.

In the case of content of food components is $2 \%$ or less, it is allowed to specify them in any order after any the components, that amounts more than $2 \%$, unless otherwise provided by the technical Regulations of the Customs Union on certain types of food products.

When a flavor exists in the food product marking composition must include the word "flavor (s)". Invented name of the food products for flavoring of food products comprising may be omitted.

When a food supplement exists in the food must be specified functional (technological) purpose (acidity regulator, stabilizer, emulsifier, other functional (technological) purpose) and the name of a food additive that may be replaced by the index of food supplements according to the International numerical system (INS), which is included in the FAO / WHO Food Codex Alimentarius. or the European numerical system (E). If food additive has different functionalities, should be stated the functionality corresponding to the purpose of its use. It is not required to specify carbon dioxide used as a component in the production of food when inscription "Carbonated" or similar is included in the labeling of food products.

Components (including nutritional supplements, flavorings), dietary supplements, the use of which may cause allergic reactions or contraindicated with certain types of diseases should be indicated in the labeling of food products, irrespective to their quantity.

For food products produced using GMOs including those, not containing a deoxyribonucleic acid (DNA) and protein should provide information: "genetically modified product "or" products derived from genetically modified organisms "or" the product contains components of genetically modified organisms". 
In case the producer of manufactured food products don't use genetically modified organisms, the content of $0.9 \%$ or less of GMOs in food production is accidental or technically unavoidable impurities, and such food products are not food products containing GMOs. When labeling such a food product information on the presence of GMOs is not specified.

The "nutritional value of the product," according to the existing regulations, includes:

- information on the amount of protein, fat and carbohydrates;

- information on the number of micro-and macro-elements, vitamins and other components used to enrich the product;

- information about the amount of lactic acid, probiotic bifidobacteria and other microorganisms as well as yeast (for dairy products, and fermented);

- $\quad$ information on the energy value of the product;

- additional information.

- Nutritional dairy lead per $100 \mathrm{ml}$ or $100 \mathrm{~g}$ of product. Allowed to provide information on the nutritional value of the product based on one serving, provided the amount of such portion. Portion is considered to be a certain amount of product that can be eaten at one meal. The amount of product that is a portion of a particular product type, specified by the manufacturer.

The amount of vitamins and minerals in food must be specified if the vitamins and minerals added to food products during its production. In other cases, vitamins and minerals in food products may be indicated in respect of vitamins and minerals, which are $5 \%$ or more of the values that reflect the average adult daily requirement of vitamins and minerals substances in an amount of $100 \mathrm{~g}$ or $100 \mathrm{ml}$ or per one serving of food products .

The element "of fat" is one of the elements that are used exclusively in the labeling of dairy products regardless of the requirements of regulations. For information on the mass fraction of fat in the product labeling indicates the values and percentage of fat mass units $(\%)$.

Information on the food product characteristics also includes information on the energy value. Energy value is the amount of energy released from the food product in humans for its physiological function. The energy value of the product must be brought to labeling information in joules $(\mathrm{J})$ and calories (cal) or in multiples of these quantities ( $\mathrm{kJ}$ kcal). The energy value of the product is determined by calculation, using the conversion factors adopted. Values of food and energy value shall be rounded off in accordance with the provisions of TR CU 022/2011. 
Information on the date of manufacture (production) and the expiration date is an important marker evidence of safe use of the product.

The date of manufacture of the product should be determined after the end of the process of production. Typically, the end of the process is specified by the manufacturer in the production technical documentation (instruction manual). Thus the point, from which to start counting the shelf life of the product is fixed. This is especially important for highly perishable products.

The essential condition to ensure safety for human health and preservation of consumer characteristics of the product is compliance with established for each type of product temperature and humidity storage options, including the rules for handling.

Storage conditions, namely storage temperature, are dependent on the type of product. Since the range of food products is very different, the temperature conditions may vary and it will depend on the type of product, from the qualitative characteristics (consumer properties) of the product from the manufacturer's recommendations, etc.

In accordance with TR CU 022/2011 information about the document, according to which the product is manufactured, is related to the nature of the additional information. Vertical regulations established compulsory reference document information in the labeling information. At the same time for the products imported to the territory of the Customs Union from third countries, this information is not obligatory.

The documents according to which the product is manufactured and can be identified, and the designation is carried to the label are: interstate standards of the form of technical specifications, the national standards of the form of specifications, standards of the organization (establishing requirements for the product) and the actual specifications.

Labeling should contain recommendations and (or) restrictions on use, including cooking of food in case its use without these guidelines or limitations is difficult, or it may cause harm to the health of consumers, their property, reduce or loss of taste properties of food products.

Labeling also should provide information about the presence of food components produced using genetically modified organisms (hereinafter GMOs).

Non-alcoholic beverages containing caffeine in an amount greater than 150 $\mathrm{mg} / \mathrm{l}$, and (or) medicinal plants and their extracts in an amount sufficient to provide a tonic effect on the human body, should be labeled with an inscription "not recommended for use by children under the age of 18 years, 
during pregnancy and breast-feeding, as well as for people suffering from nervous irritability, insomnia, hypertension ".

Labeling of food products may contain the following additional information:

- Invented name of the product;

- trademark;

- information on the holder of the exclusive right to the trade mark;

- name and address of the licensor;

- appellation of origin of the food;

- signs a voluntary certification;

- recommendations for the use or the manufacturer's recommendations Nowadays there is considerable amount of packaged food products with the signs of voluntary certification. Most often they are signs confirming the certification of production systems according to ISO 9000 and ISO 22000.

Labeling of food products should be clear, easy to read, accurate and not misleading consumers (purchasers), with inscriptions, signs, symbols must be contrasting to background on which the marking is affixed. Should be applied a marking method, which will ensure its preservation for the duration of the shelf life of food products in compliance with storage conditions established by producer.

The inclusion of bar code labeling of products is not regulated by the legislation of CU. However, in today's market to handle large amounts of data is possible only with the use of information and computer technologies. Ensuring the identification of objects in the supply chain is possible with the use of technology based on the use of bar code - a unified system of communication of manufacturers, logistics companies and trade organizations. Thus, with the help of bar code is possible to account products and integrate a global control of their movements.

\section{CONCLUSIONS}

The establishment of uniform standards and regulations for the production and labeling of food products in the framework of the Customs Union of Russia Belarus and Kazakhstan led to the unification of commodity markets for food products of these countries and to the harmonization of their legislation, increase food safety and consumer awareness. 


\section{ACKNOWLEDGEMENTS}

NUTRILAB - NUTritional LABeling Study in Black Sea Region Countries receives research funding from the European Community's Seventh Framework Programme (Contract No319846).

\section{REFERENCES}

1. EurAsEC today. Integration Committee Secretariat of the Eurasian Economic Community (EurAsEC), 2011. 27p. Retrieved February 3, 2014, from http://www.evrazes.com/i/other/EurAsEC-today_eng.pdf

2. Customs Union Technical Regulation 005/2011 "On the safety of the packaging" (in Russ.) Retrieved September 21, 2013, from http://www.tsouz.ru/db/techreglam/Documents/TR\%20TS\%20Upakovka. pdf

3. Customs Union Technical Regulation 021/2011 "On Food Safety" (in Russ.) Retrieved February 3, 2014, from http://www.eurasiancommission.org/ru/act/texnreg/deptexreg/tr/Docume nts/TR\%20TS\%20PishevayaProd.pdf

4. Customs Union Technical Regulation 022/2011 "Food products in part of their labeling" (in Russ.) Retrieved February 3, 2014, from http://www.eurasiancommission.org/ru/act/texnreg/deptexreg/tr/Docume nts/TrTsPishevkaMarkirovka.pdf

5. Customs Union Technical Regulation $027 / 2012$ "On the safety of certain types of special food products, including dietary medical and dietary prophylactic nutrition" (in Russ.) Retrieved February 3, 2014, from http://www.eurasiancommission.org/ru/act/texnreg/deptexreg/tr/Docume nts/P_34.pdf

6. Customs Union Technical Regulation 029/2012 "Safety of food additives, flavorings and processing aids"(in Russ.) Retrieved February 3, 2014, from

http://www.eurasiancommission.org/ru/act/texnreg/deptexreg/tr/Docume nts/P_58.pdf )

Vol. XVIII (2014), no. 1 